Article

\title{
Children enacting idioms of witchcraft and spirit possession as a response to trauma: Therapeutically beneficial, and for whom?
}

\section{Ria Reis}

University of Amsterdam and Leiden University Medical Center

\begin{abstract}
This article examines children's enactment of spirit possession idioms and witchcraft in Africa including the meanings such idioms provide and the local healing resources they mobilize. Idioms of haunting spirits in Northern Uganda and witch-children elsewhere in Africa can be interpreted as manifestations of social crises and mass traumatic stress. On the other hand, such idioms also allow children to articulate, reflect upon, and communicate the complex feelings resulting from their precarious positions within families and communities under duress. With the help of Dow's transactional model of symbolic healing, this article explores obstacles to the effectivity of the rich variety of symbolic healing available for haunting spirits in Uganda and points to the generational gap between children and their families and communities. Elsewhere, witchcraft idioms may act as a healing resource at the group level, but at the expense of the accused child. The idioms of evil spirits and witchcraft speak of these children's navigation of the moral universe of their postconflict communities. Given that children's appraisal of their experiences through these notions may also exacerbate their anxiety, interdisciplinary research examining the microprocesses that lead to children being haunted or accused, including emotional and physiological levels effects, is urgently needed.
\end{abstract}

\section{Keywords}

Africa, child idioms of distress, child witch, haunting spirits, symbolic healing 


\section{Introduction}

In many African countries, traumatic stress resulting from civil conflicts, poverty, and epidemics may be manifested through symptoms that are locally understood to originate from spirits or witchcraft. From Lewis's (1971/2003) treatise onwards, an extensive body of anthropological and psychiatric literature has described how such cultural idioms of distress express, mediate, or mitigate extreme stress. The present inquiry examines children's enactment of spirit possession idioms and witchcraft in diverse African settings and the mechanisms through which these idioms may contribute to the mitigation or resolution of traumatic stress. The main objective of the article is to examine how children experiencing social adversity navigate their predicaments. Ensink and Robertson (1996) argue that distress idioms diagnosed in children do not function as discrete diagnostic entities, but rather as parts of broad and occasionally inconsistent explanatory models. The present inquiry focuses on children's use of locally available idioms as discursive tools to give meaning to their social suffering, as well as on therapeutic mechanisms these idioms may give rise to (Obeyesekere, 1991; cf. Kirmayer \& Blake, 2009, pp. 39, 49), rather than addressing the saliency of diagnostic constructs for phenomenological processes. Children's cultural idioms of distress are discussed as a contextually etcetera relevant metaphorical language used to communicate social suffering which cannot be expressed otherwise due to its implicit threat to the structures surrounding the sufferer (De Jong \& Reis, 2010; Nichter, 1981).

The main objective of this study is to examine this extent and ways in which cultural idioms of spirits and witchcraft function as local healing resources for children under duress. What meanings of suffering do such idioms provide and which local therapeutic mechanisms may be mobilized by the children who enact them? Haunting spirits in Uganda and the widespread phenomenon of childwitches are two contemporary distress idioms which will be discussed in further detail. These idioms represent two types of children's increasing involvement in "the occult," which is often referred to in the double phrasing of "witchcraft and spirit possession" (cf. Geschiere, 1997, p. 14; Ranger, 2007).

The present study reflects on published work in two fields of medical anthropology: spirit possession in symbolic healing in Africa, and child health from a child-actor perspective. These fields were research foci of the author and her students over the past two and half decades. ${ }^{1}$ Key questions in these fields regarding the role of agency and learning in behavioral communications of distress have lead to a collaborative project on child distress idioms in Nepal, Surinam, Swaziland, and Sierra Leone. This work is currently in progress, and the present study will serve as preparatory research for this project.

\section{Children, spirits, and witches}

In social worlds dominated by the belief that evil lurks in human relationships, children may also be implicated in the diagnostic and curative processes aimed at 
redressing social wrongs. In Northern Uganda, Acholi children complain of cen, spirits of people who died during the war and who haunt the living until they are appeased (Akello, 2010; Akello, Reis, \& Richters, 2010; Akello, Richters, \& Reis, 2009; Angucia, 2010; Anyeko et al., 2012; cf. Liu Institute, Gulu District NGO Forum, and Ker Kwaro Acholi, 2005; Neuner et al., 2012). Those that suffer from cen may be innocent kin, such as a child who is harassed at night by the spirit of his slain mother demanding a funeral rite or asking her grieving son to join her in the spirit world. Cen typically haunt their murderers as well, such as children who were forced to kill their kin, neighbors, or other children at the traumatic event of their abduction by Lord's Resistance Army (LRA) that rebelled against the central government. Former child soldiers are particularly susceptible; even if they do not suffer from any symptoms, their victim's spirits are assumed to follow them (cf. Baines, 2007, p. 109). This leads to considerable stigmatization, for cen are also contagious, spread through contact with an infected person or by accidentally stepping over human remains. The many random killings during the war have caused the country to be infested with cen (Angucia, 2010, p. 186; Liu et al., 2005, p. 11). Cen manifest in children as nightmares, sleeplessness, headaches, hearing voices, images of violent men, and disturbing recollections of witnessed violence. Their anger may also lead to illness or death, for instance of the child of a former child soldier (Akello, 2010; Akello, Richters, \& Reis, 2006). Cen are associated with multiple feelings, such as guilt, fright, or sadness; children experiencing these symptoms are often diagnosed with severe depression and/or PTSD (posttraumatic stress disorder; Akello et al., 2009; cf. Neuner et al., 2012). ${ }^{2}$

In other African countries, witchcraft accusations increasingly target children. De Boeck (2005) extensively described the phenomenon in Kinshasa, Democratic Republic of the Congo (DRC), but reports from other countries have also emerged, including some postconflict countries (e.g., Angola, Sierra Leone), and some outside of this category (e.g., Benin, Ghana, Nigeria, Tanzania). Cases of witchcraft accusations have also been reported among African immigrants to European countries. Stobart (2006) discusses 38 cases involving 47 children in the United Kingdom. Many had a distinguishing personal quality, such as above average intelligence or, more commonly, a chronic or life-threatening illness or disability (cf. Cahn, 2006, p. 423). Most children showed symptoms of depression. In Ghana, Adinkrah (2011) analysed newspaper reports of 13 cases involving 18 children (aged 1 month to 17 years) among the Akan. Children's kin played the major role in accusations, triggered by family misfortune, such as death, illness, or a lack of business success. Again, children with distinguishing qualities were at risk. As the Akan believe witchcraft is passed on through generations, children involved were considered to be infested with witchcraft from birth. Some of the children confessed to evildoing. De Boeck describes the DRC children's elaborate descriptions of their involvement in the misfortunes and death that had afflicted their kin as well.

Both haunting spirits and child-witches have historical antecedents. Elderly Acholi in Northern Uganda remember how a warrior would kill an enemy and 
lure the angry spirit, or cen, to his home, so that he could ritually incorporate it amongst his other spiritual powers. More generally, cen resonates with massive experiences of possession by roaming spirits of the dead from the beginning of the 20th century onwards in Southern Africa. Examples include amafufunyane, bands of foreign spirits harassing Zulu women caused by sorcery involving cemetery soil, or indiki, that is, amandawe, spirits of men for whom no funeral rites have been performed, the fate of many labor migrants (Hammond-Tooke, 1986, pp. 162-164; Ngubane, 1977, p. 144; Reis, 2000; van Nieuwenhuijsen, 1974, p. 12). Spirits of slaughtered enemies not only cause misfortune and disease; they may be transformed into healing powers in the afflicted. Shave spirits among the Shona belong to this category, as well emandzawe manifesting in Swazi healers, and gamba spirits manifesting in Mozambican women (Honwana, 2002; Igreja, 2007; Igreja et al., 2010; Reis, 2000). Some spirits typically haunt children. Reynolds (2005, p. 91) describes Zimbabwean child-messengers for the guerrillas fighting the Rhodesian army, who exercised arbitrary power over the population. After the war, many such children sought healing from the spirits of innocent civilians in whose deaths they were involved. Such spirits can be contracted by chance as well, since the country is infested by armies of spirits unhappily roaming due to the many wars that killed them.

Witchcraft accusations against children are not a new phenomenon. ${ }^{3}$ Like the Akan, the Azande considered witchcraft a substance, an ontological propensity inherited from one's parents and therefore present from a young age onwards (Evans-Pritchard, 1937/1976). Bamileke child-witches in Cameroon caused sickness and death, and sometimes fell sick and died themselves as a result of their evildoing (Brain, 1970). The embodied and emotive language through which children express their suffering is thus rooted in shared sociohistorically meaningful idioms. Recently, children have become an increasingly prominent category in relation to spirits and evildoing. If these occult phenomena are considered idioms of distress, we must ask what distress is at stake. What do children experience, express, and communicate?

\section{Reflections of social suffering}

Within the field of anthropology, accusations of witchcraft and spirit possession are typically considered windows to tensions in social relations. They tend to follow structural ambiguities and contradictions in social relationships. Witch-cleansing movements, "epidemics" of spirit possession, and similar phenomena are thought to reflect collective distress in the face of rapid societal change. Ngubane (1977, p. 147) interpreted amafufunyane as a symbolic reflection of the disintegration, marginalization, and fragmentation of local worlds resulting from rapid modernization and the penetration of capitalism in Southern Africa. It is apparent that children in the contemporary settings in question were also massively distressed due to severely damaged social fabrics, extreme poverty, social deprivation, and abuse. 
Most Ugandan children complaining of haunting spirits of the dead were born and grew up during a devastating civil war. In Acholiland, the LRA under Joseph Kony became infamous for its gross atrocities against civilians, including the abduction over the years of some 30,000 children and youth who were forced into child soldiering (Baines, 2007; Finnstrom, 2006). The conflict spread throughout the region and resulted in a severe humanitarian crisis. The impoverished population was displaced and residing in medically underserviced and frequently attacked camps. Many children, abducted and not abducted, experienced or witnessed violence, were orphaned, or lost family members to violence or HIV/AIDS. At the peak of ongoing violence and nightly abductions, some 40,000 children walked from their rural homes to the relatively safe cities to spend the night in shelters (Baines, 2007; Roberts et al., 2009; van Acker, 2004). Children as young as 12 years old headed households and lived in extreme poverty. Such children and formerly abducted children were very vulnerable to haunting spirits. ${ }^{4}$

Living circumstances of children in the DRC are similarly bleak. Two decades of war have led to an estimated five million deaths, half of them children, due to direct violence and destruction of villages, health systems, and harvests, resulting in uncontrolled epidemics and widespread malnutrition (De Boeck, 2005). Recent data point to an estimated 400,000 raped girls and women (Peterman, Palermo, \& Bredenkamp, 2011). Kinshasa, DRC is the site of continuing structural violence and political insecurity, ongoing violence in communities and in families, mass migration, and demolished extended family safety networks (De Boeck, 2005). Elsewhere, communities involved in accusations that target children share risk factors such as high rates of structural violence, political insecurity, economic marginalization, and social fabrics destroyed by massive migration, increasing inequity, and widespread child neglect and abuse (Adinkrah, 2011, p. 743; cf. De Jong, 2010). Adinkrah (2011, p. 743) describes widespread child neglect and abuse in rural Ghana, structural recourse by parents and teachers to corporal punishment, and strict norms of obedience and submissiveness in the face of deep poverty and marginalization.

De Boeck (2005; cf. Geschiere 1997) suggest that the phenomenon of child witches originates from profound transformations in the realm of kinship. Children, he argues, have never before been so prominently visible in the urban landscape, and dangerously powerful in both a military and economic sense. It is precisely their presumed agency that renders them vulnerable to witchcraft accusations. Whereas changing gender relationships led to the increased vulnerability of women to witchcraft accusations in the past, rapid changing intergenerational relations in urban contexts now fuel accusations against children (Adinkrah, 2011; De Boeck, 2005; cf. Seekings, 2006). In line with earlier anthropological interpretations of waves of spirit possession and witch-cleansing movements, both the haunting spirits of children in Uganda and witch-children in Kinshasa and elsewhere may be considered "symptomatic" of underlying societal crises. ${ }^{5}$ 


\section{Children's moral universes}

An interpretation centered around large-scale social processes avoids the complex issue of children's own volition in their culturally patterned collective communications of distress (cf. Kirmayer, 1989, p. 335), and may not reflect what is at stake for the children involved (cf. Kleinman \& Kleinman, 1991). Meanwhile, speaking of children's "use" or "enactment" of idioms of distress (e.g., Hollan, 2004, p. 76) implicitly attributes some intention and moral responsibility to children in transforming their distressful state into a symbolic language (Kirmayer, 1989; Nichter, 2010). A helpful position to overcome the seeming diametrical contradiction between symptom and volition (Kirmayer, 1989) - or, victimhood and agency (cf. Christensen, 2000) - is offered by Sherry Ortner (2006, p. 110). Carefully broaching the topic of consciousness in agency and avoiding a diametrical opposition between structure and agency, she maintains that "agency... takes shape as specific desires and intentions within a matrix of subjectivity - of [culturally constituted] feelings, thoughts, and meanings." The question to what extent this can be applied to children merits further discussion.

There is an extensive body of literature discussing children's capacity as social actors and meaning makers. Over three decades of theorizing and empirical research with rather than on children has shown that even very young children make sense of experiences and act intentionally towards others and in the present moment, and they should therefore be considered social actors with agency in their own right. ${ }^{6}$ An early and compelling example is provided by Bluebond-Langner's groundbreaking research (1978) on how terminally ill children come to know that they are dying. She describes how children knowingly engage with their caretakers in "mutual pretence," a shared silence over the approach of their death, not based in ignorance or avoidance, but as a conscious strategy to prevent hurt in the people that care for them. Bluebond-Langner's description of children's readings of signs of their imminent death and their navigation across the terrain of their unfolding journey towards it is a moving example of the moral capacities of young children.

In his research on the effectiveness of a classroom based intervention for children in postconflict settings, Tol (Tol, Jordans, Reis, \& De Jong, 2009; Tol, Reis, Susanty, \& De Jong, 2010) found that in all researched settings (Burundi, Indonesia, and Sri-Lanka) children shared ideas about the effects of the conflict on their health and well-being with their peers. However, these ideas did not fully overlap those of adults, for example, in symptoms of conflict-related stress, its causes, and strategies to deal with it. In relation to Northern Uganda, Akello (2010) describes the health strategies of internally displaced children in childheaded households, and children taking care of HIV positive relatives. They harbored elaborate ideas about the causes of common illnesses and diseases that befell them and other children, and devised strategies to find solutions to their suffering. They economized in order to buy medicines, and sought help from healers, doctors, churches, and NGOs. Akello et al. (2009) argue that these children, like the dying children in Bluebond-Langner's study (1978), were active accomplices in the 
conspiracy of silence that prevented them from expressing negative emotions regarding their losses and emotional pain directly. Four processes were identified. Next to victim-blaming and self-blaming, the authors found a competitive wish to be or appear strong by hiding emotional distress (coined "mimetic resilience"), as well as a strategy to hide feelings in order to shield others from mirroring similar distress (coined "mirroring resilience"; cf. Reynolds, 2005, p. 95). Children as young as 10 years old discussed their emotional wounds in terms of sadness, emotional distress, and bleeding hearts. They also discussed what motivated them to deal with such feelings in any particular way.

Discussing the self, Hollan (2004, pp. 63-64), speaks of "the human ability to evaluate one's own thoughts, feelings, behaviors, and intentions (and those of others) relative to some standard of conduct." Which standards of conduct do children orient themselves towards when they express and give meaning to their distress in symptoms that speak of spirit possession and witchcraft? In other words, what moral universe are they navigating? There is a wealth of information to be gleaned from the in-depth descriptions of the life worlds of Ugandan children haunted by spirits of the dead, children elsewhere in Africa, and children among African communities in Europe who are accused of and sometimes confess to witchcraft. For example, we learn that a shared core of this universe is the feeling/notion that evil intentions, jealousy, and conflict, in short the evils that lurk in human relationships, directly influence health and fortune; and that by being born human, one is immediately partaking in a moral universe where the intrahuman (the intrapsychic) is inescapably intertwined with the interhuman (the social) and suprahuman (ancestors, spirits, witches). In this moral universe children's subjectivity is immediately embedded in social and spiritual relationships characterized by conflicting and contesting motives and desires.

The moral universes navigated by children when they enact cen or witchcraft beliefs may also be fundamentally different, however (cf. Ranger, 2010). Witchcraft beliefs in Africa vary widely, and from the 1970s onwards, anthropologists have tried to understand the relation between these variations and the sociostructural environments in which they feature (e.g., Douglas, 1973; Marwick, 1950). Empirical data on how child-witches fit in is scarce, but the evildoing at stake seems to be ontological: the issue is not so much about doing evil as about being evil. Witchcraft in witch-children is considered a substantial part of their being; they are evil embodied, fundamentally different. This existential fissure between good and evil here takes shape not in the tension between insiders and outsiders (such as when evil is projected upon foreigners or people from a different ethnic group). It emerges within the intimate microrelations in which children are embedded; accusations originate from their closest relatives. It is exactly these relations that evolve under extreme stress, caused by deep poverty, marginalization, fragile sociopolitical fabrics, and loss of hope, all of which are exacerbated in some communities by the devastations of war and cycles of violent ethnic conflict.

However, accused children share the same moral universe as their accusers. Like any other actor, they appraise their experiences and act upon the world through 
cultural schemata that cannot be conceived of as external to their selves, and that are as much cognitive (e.g., attributions of witchcraft or spirits) as emotional and embodied (Hinton \& Good, 2009; Kirmayer, 1989, p. 330; cf. Ortner, 2006, p. 63). Brain (1970) was interested in the reasons why Bamileke children confessed to witchcraft. His explanations center around consciousness; boundaries between rationality, fantasy, and delusions; and the psychological effects of physical deprivation (e.g., trance). These issues were a core element of the anthropological and transcultural psychiatric debates at the time (Kiev, 1972; cf. van Dijk, Reis, \& Spierenburg, 2000). He also took interest in children's emotions and observed great anger. This insight may provide a clue for understanding what is at stake for children confessing to be witches in the DRC, Ghana, and other African communities. Where norms of obedience and submissiveness rule, anger is a dangerous emotion for victims of abuse to express (cf. Reis, 2011). This would explain why children need a cultural idiom of distress, a metaphorical language to communicate social suffering that cannot be expressed otherwise due to its implicit threat to the structures that embed the sufferer (De Jong \& Reis, 2010).

The moral world that features cen is quite different, for haunting spirits do not unambiguously point to accountability. Spirits of the dead follow their murderers, but may attack anyone crossing their path in their unhappy roaming. In the imagery of cen, boundaries between victims and aggressors are blurred. This reflects the real world; children who have killed often have been forced to do so in order to make them willing tools of war. It is also important to remember that warriors enhanced their powers by killing their enemies. Warriors would take an item or piece of cloth of their victims, thus luring their spirits home and incorporating them into their other spiritual powers. ${ }^{7}$ Former child soldiers report that they did not suffer from cen whilst under arms, but only after returning to their communities. On the battlefield, in the context of armed combat, reigns a moral universe in which killing another human being is not intrinsically wrong. As an idiom of distress, cen are manifestations of disputable and contextual accountability. Children's struggles with feelings of guilt, sadness, and anxiety are a consequence of society's reluctance to come to terms with its violent past. This lack of clarity regarding accountability allows children to express, reflect, and act upon their existential anxieties regarding their own moral personhood (cf. Akello et al., 2009; Honwana, 2005). Guilt is too crude a concept to be used to describe the emotive struggles with moral personhood expressed in cen. A child haunted by the unhappy spirit of his slain father who must roam until his last rites have been performed expresses a complex combination of angst for the world of the dead, mourning, and feelings of failure. This is very different from the mixed feelings of accountability, anger that one was forced in this terrible wrongdoing, and the confusing fact that they do not experience cen when under arms that former child soldiers may experience. $^{8}$

Children's appraisal of their traumatic experiences and complex emotions through notions of spirits and witches enables them to give meaning to these experiences, and to contemplate themselves, others, and their place in the world 
(cf. Ortner, 2006). Through these notions, suffering is expressed, helping children communicate their stakes to relevant actors in culturally specific environments. In what way and to which extent do children and their families and communities derive local therapeutic pathways from these communications? Through which mechanisms can these pathways help resolve what is at stake for them?

\section{A ritual repository}

Different therapeutic resources are available to children with cen in Northern Uganda. The widespread use of sedatives and sleeping pills available in pharmacies by children in Gulu alerted Akello (2010) to the distress of children haunted by cen. Children also access herbal therapies. Atika, the leaves of the olwedo tree, may ward of mosquitoes as well as nightmare-causing spirits of the dead (Akello, Richters, \& Reis, 2006; Liu et al., 2005, p. 12). When these measures do not suffice, ritual healing is used. Descriptions of such rituals in different ethnographies and reports generally corroborate the primary findings of an in-depth action-oriented 2005 research project (Liu et al., 2005), which is used as a principle reference. ${ }^{9}$ The focus of this project was traditional approaches to justice and reintegration. The described cleansing, as well as the compensatory and restorative healing rituals, however, had social and individual functions long before the cycles of civil war. After the war they were carried out, sometimes in an adapted form, especially for returning formerly abducted children to help them reintegrate with their families and communities (Baines, 2007; cf. Akello, 2010).

On individual level, Guru lyel, the last funeral rite, needs to be performed to placate an unhappy roaming spirit whose owner died a bad death away from home, and whose surviving kin had not been able to carry out the ceremony, as was the case for many children who lost their parents (Akello et al., 2010; cf. Ocitti, 1973). Lwoko pig wang, the "washing of tears," is a welcoming ritual ceremony for a person who was mistakenly thought to have died. Thoughts of death attracting cen are ritually washed away along with the tears shed by the mourning family. Well known among formerly abducted children, Nyono Tong Gweno, the "stepping of the egg" ceremony, is another welcoming ritual. Liu et al. (2005) describe it as originally intended as a cleansing and welcoming ritual for individual members of the family returning home after travel, which was remodeled in 2003 into communal ceremonies simultaneously welcoming back huge groups of displaced people, ex-combats, and rebel commanders. No mention is made of the ritual specifically targeting haunting spirits, but they may belong to the vague category of external influences encountered in the bush that the ritual aims to cleanse the returnee off (Liu et al., 2005, p. 27; cf. Baines, 2007; Mpyangu, 2010, p. 112). In its modern form, the ritual can also be seen as the outcome of a voluntary restorative traditional justice process involving a confession of truth that will eventually lead to compensation (Angucia, 2010; Baines, 2007; cf. Anyeko et al., 2012).

Welcoming rituals for individual children are usually performed by the family at home, but if a former child soldier indeed confesses to having killed, or if the 
symptoms of cen are pervasive, a consulted healer may decide to perform Yubu Kum or Ryemo Jok. The first is a "cleansing of the body" ritual, in which the spirit is ritually transferred from its human victim to a scapegoat; a chicken, goat, or blood of a sheep. ${ }^{10}$ In the latter sacrificial ritual, a healer slaughters a chicken or goat and offers it to the spirit by throwing its body where the cen is thought to dwell (Liu et al., 2005; cf. Angucia, 2010). Ritual resources are also available when geographical areas are infested by cen; Ryemo ojwee or Ryemo Gemo are nightly rituals organized by Elders and senior women, involving general noisemaking to expel cen from the area towards the sunset. In contrast, in the Tumu Piny/Moyo Piny/Moyo Ryemo cen ritual, the sacrifice is made to the ancestors for appeasement in cases of widespread contamination, particularly at massacre sites (Baines, 2007; Liu et al., 2005; Mpyangu, 2010).

Acholi culture, personified by healers and Elders, has a ritual repository that may provide various healing resources for children to deal with the traumatic stress expressed in the cen idiom. From an analytical viewpoint, they address distress on five different dimensions of human being and becoming (cf. De Jong \& Reis, this issue). The superhuman dimension is common to all rituals, which all address problems in the relationship of the living to spirits of the dead. All rituals also address the intrahuman dimension of cen, depending on the person's personal accountability, in varying combinations of externalizing procedures. These include cleansing, exorcising, and chasing away, as well as addressing internalized guilt, sadness, and anxiety by providing last funeral rites, confession, sacrificing. These rituals may also include restoration of belonging through welcoming and cleansing. The recognition of the emotive and moral complexity of cen complaints is particularly impressive. When ritual specialists decide that a scapegoat, rather than a sacrifice to the spirit or God, is needed to expel the spirit, they skillfully navigate this complex moral emotive universe.

Welcoming and cleansing rituals can be described as resources particularly helpful for the interhuman, or the healing of human relations, for they reintegrate the returnee into his webs of social relations, and restore belonging and connectedness. The extrahuman dimension, where the natural environment is at stake, is addressed through the rituals that cleanse the widespread geographical contamination of cen. All rituals are aimed at the fifth temporal dimension where hope and fulfillment of desires reside. The aim is fruition: removing the obstacles that prevent individuals, families, and communities to grow, flourish, and reproduce (van Dijk et al., 2000).

\section{Healing effectivity}

How effective are these approaches? Data on the effects of therapies for cen are mostly anecdotal and equivocal, but this is in line with the overall lack of scientific evidence for the effectivity of psychosocial and mental health interventions for children in postconflict areas (Jordans, Tol, Komproe, \& De Jong, 2009). One serious limitation is that nonabducted children who suffer from cen are the focus 
of communal restorative or healing activities to a much lesser extent than former child soldiers whose violent past poses an implicit threat to the peaceful fruition of communities. For the sometimes elaborate cleansing and other healing rituals to be carried out, children need family and community support and financial assistance, and these are exactly the support structures that may be damaged, missing, or perhaps even implicated in the suffering of children. Liu et al. (2005) are cautiously optimistic about the self-reported mental and relational effects of cleansing rituals on former child soldiers, as well as about the effects perceived by their families and communities. A positive effect on cen is alluded to when former child soldiers report that they suffer fewer nightmares after their interventions. The former child soldiers, all now young adults, retrospectively interviewed by Angucia and her team (2010), and the formerly abducted girls interviewed by Mpyangu (2010), also reported having benefitted from such rituals. However, Akello et al. (2009, pp. 186-187) found that the great majority of children who were liberated from the LRA and reintegrated into their families between 2004 and 2005 left their communities within 3 months of their ceremonies, and in that period more than $70 \%$ of prisoners in the Gulu juvenile crime unit were former child soldiers, acutely indicating failure of their integration processes. Formerly abducted children felt that their need to come to terms with their own accountability was not filled by wellmeaning parents, communities, or NGOs who provided restorative rituals for them.

In organizations specializing in culturally sensitive and effective interventions for restoration of justice, peace-keeping, and integration in postconflict settings, considerable hope is invested in traditional communal healing resources. Dow's (1986) analysis of the processes involved in symbolic healing describes what is needed for such healing to work. Dow maintains that therapeutic mechanisms such as suggestion and persuasion, catharsis, social restructuring, and psychochemical actions ${ }^{11}$ offer important but only partial explanations of the symbolic healing process. His theory describes the common structure of symbolic healing in four phases. First, the sufferer and the healer or therapist must share a generalized model of experiential reality that Dow called its mythic world. Second, the sufferer must be persuaded by the healer or therapist that his problems can be defined in terms of this model. Here the quality of the relation between sufferer and healer is crucial, since trust is necessary for this persuasion to occur. The healer then attaches the patient's emotions to transactional symbols which are particularized from this model, and finally manipulates the transactional symbols to help the patient transact his or her own emotions. This transactional process can be understood within an ecological model of hierarchical systems, progressing from the basic molecular system upward to the body system, the self system, the social system, and the ecosystem. Symbols are codes that, because of their polysemic nature, may facilitate communication between the system levels of the social and the self. Manipulation of symbolic parameters at the social level affects processes in the self and unconscious-somatic systems. Emotions are the generalized media that link the self and the somatic systems (Dow, 1986). 
Following Dow's model, the crux of the matter for the effectivity of symbolic healing is in the prerequisite that children share culturally specific internalized schemas through which they feel and think about their world with their families, communities, and healers. This is far from straightforward in Northern Uganda. The available ethnographies provide some insight in the local theories of why communal rituals are not as successful as they were hoped to be. Liu et al. (2005) describe a picture of intergenerational tensions resulting from the long duration of the civil war, displacement, and social fragmentation. Children suffering from cen grew up in displaced communities lacking normal transference of cultural knowledge and values, and children and young people have fragmented knowledge of the spirit world. Spirits are relayed through storytelling, one of the methods of the explicit transgenerational transmissions of moral notions (Dickson Gomez, 2002; cf. Tize, 2011), but extended families no longer gather around fireplaces to hear tales and lessons from elders. Abducted children obviously had no access to such teachings during their years in the bush. Liu et al. (2005) found that rituals were self-reportedly more effective if the returning child knew and understood the significance of the ritual. They argue that further effectivity could be reached if these children were more fully informed of the meaning behind traditional rituals (Liu et al., 2005). In terms of the symbolic healing process, however, being "informed" about meanings is not equivalent to sharing these meanings as internalized emotive and moral orientations towards oneself and the world. It is unlikely that interventions that make use of sophistic symbolism derived from ancient notions could deeply impact children's embodied experiences expressed in cen. Children relay the experiences of civil conflict, poverty, marginalization, instability, and the rapid changes in their environments to their parents and communities. But they grew up under this duress and their subjectivities became constituted in ways that distance them from effectively tapping into the rich repository of healing resources of Acholi culture.

Other local idioms are competing as well. Local Christian churches may acknowledge the spirit hypothesis; they may believe that independent spiritual entities can cause afflictions. However, they consider such entities as demons to be exorcised and condemn traditional rituals that try to appease them as backward and evil. The fact that many former child soldiers return to their communities as reborn Christians hampers the effectivity of these rituals as a restorative justice mechanism, and, perhaps as healing mechanisms as well (Liu et al., 2005; cf. van Duijl, Cardeña, \& De Jong, 2005, p. 392).

Intergenerational tensions also impede the second step in the symbolic healing process. Trust is a necessary prerequisite for allowing the manipulation of symbolic parameters, in this case cen, to translate to the self and unconscious-somatic system so that healing may occur. However, the Elders' authority is eroded in Acholiland. Their own displacement, poverty, and sometimes problems with alcohol make them difficult to respect (Baines, 2007). On the other hand, negative labeling of youth by adults and stigmatization of formerly abducted children are also not 
conducive to the trusting relationship on which rituals must be built (Liu et al., 2005).

Paradoxically, children's communities and those that strive for restorative justice also seem to reject part of what was at one time a shared moral world. Conspicuously absent from the listing of adapted local resources for traditional justice and healing is the ancient ritual enacted by an Acholi warrior who unites the angry spirit of his slain enemy with the other spirits (ancestors, enemy sprits) whose powers he can draw upon. Mastering, welcoming, and accommodating cen instead of expelling them is an effective strategy in a moral universe where the killing of another human being is not intrinsically wrong. Accommodating spirits that interfere with life is a common strategy in many African healing cults (Janzen, 1992; Turner, 1968/1981; Willis, 1999) and slain enemy spirits may be among the groups of spirits available for diagnosis and therapy (Reis, 2000). Angucia (2010) reports how former child soldiers bring a piece of cloth or small possession of their victims to the ritual where they seek healing from their cen. Former child soldiers told Akello that they did not suffer from cen whilst under arms, but only after returning to their communities. They saw their possible return to the rebels or a military career as a potentially effective healing strategy (Akello, 2010). Those striving for restorative rituals may not welcome the idea that children may not be helped to rid themselves of cen, but instead accommodate them by returning to arms.

What local therapeutic resources are available for accused or self-confessed witches? The idiom of child-witches projects evil, sometimes by the children themselves, on children who may exhibit characteristics outside of the norm, but who also simply may be available as scapegoats for communal suffering. More research is needed, but regardless of what the emotional roots underlying the idiomatic expression of self-confessed evildoing may be, one can be certain that this leads to self-destruction rather than to healing. Family members and ritual specialists may urge confession, sometimes through violent means. A confession may have a cathartic effect, but when witchcraft is considered an ontological trait, such a declaration of evil deeds can only lead to violent exorcism, expulsion, or the destruction of the child. This is, of course, what is so disturbing about the phenomenon of child-witches. These children, in an embodied way, represent the social suffering of their communities - the marginalization, destruction of social fabric, and loss of hope. These children are used or offer themselves as scapegoats whose expulsion or killing is hoped to carry away the collective evil of damaged social relations. Idioms of distress in terms of witchcraft may be a therapeutic resource for symbolically healing a family, a community, or a group, but come at a cost to the sacrificed scapegoat. Symbolic healing on the collective level cannot translate to the individual level in this case. Many authors have pointed to the problem that witchcraft concerns circular evil (cf. Geschiere, 1998). A mother losing her child may accuse another of her children, and when this child dies she may be accused as well. Scapegoats seldom solve the sociostructural problems that are projected unto them. 


\section{Conclusion}

In order to understand how idioms of distress in terms of witcheraft and spirit possession may function as local healing resources for children in Africa, we first focused on the meaning making involved. Witches and haunting spirits form part of a moral universe in which one's negative inner feelings (e.g., jealousy, anger, evil intentions) may endanger other people's health and well-being, but the stakes for children who complain of cen differ from those of child witches. In a moral universe where witchcraft is considered ontological, children who are suspected, and know themselves to harbor negative emotions over the neglect and abuse they face, find themselves in a tight spot when disaster strikes. In contrast, haunting spirits are discursive of contested accountability and allow for a relatively safe communication of feelings of guilt, sadness, and anxiety that are widely shared within their communities.

Sharing in itself may have therapeutic benefits. However, in cases where individual and communal traumatic stress is massive, it is crucial to understand the level at which resources are therapeutically effective. Perhaps notions of witchcraft and spirit possession allow children to take upon themselves or to be assigned the task of "identified patients," while their caretakers have not been able to offer them the protection they need. These notions articulate problems generated by sociopolitical upheaval in locally meaningful idioms and in this way they take on the burden of collective suffering and perhaps contribute to societal healing. This may involve individual healing, for instance when a cleansing ritual for an abducted child helps mitigate the child's distress as well as restore the social fabric and successfully reintegrate it into the community. However, individual and societal outcomes may also be diametrically opposed. The ancient warrior's way of dealing with cen by accommodating them may be helpful for an individual child who wards off his haunting spirits by returning to arms, but obviously can be considered detrimental to communal peace processes. Similarly, whereas witchcraft idioms may offer a healing resource at the group level by scapegoating and exorcising evil, this destroys the accused child.

Idioms enacted by children who complain of haunting spirits of the dead or who confess to witchcraft are reflective of children's precarious position in the quickly changing rural and urban social landscape and reflect children's navigation of the moral universe of their communities. Their communities are under duress due to the devastation of civil conflicts, political insecurity, and structural violence, as well mass migration, deep poverty, and epidemics such as HIV/AIDS. For each child, these processes translate as demolished or incapacitated family fabrics and parenting by significant others who themselves may suffer chronic grief and traumatic stress, all of which may result in social deprivation, neglect, abuse, and loss of hope. Children's externalization of evil in the notion of contagious revengeful spirits, and their internalization of evil in the notion of child-witches exemplify their problems in dealing with the grief, guilt, anger, and anxiety that result from a severely damaged moral fabric that can no longer sustain and nurture them. 
The fact that children communicate their distress through embodied symbolic language is indicative of their disempowerment and marginalization. To the extent that there is volition in cultural idioms of distress, it also speaks of their capacities to creatively process their experiences and practice reflection within the bounds of their moral life worlds, and to act upon their lives and those of others through their behavioral communications.

However, symbolic healing that makes use of the very idioms that children use to communicate their suffering may not always offer the most effective therapeutic pathway for two reasons. First, for true healing to occur, the all too real causes of children's distress must be addressed comprehensively. These include the sociostructural causes that underlie children's suffering, and the effects of trauma on the body, including the psychological or (neuro)psychiatric problems and impairments some of these children may suffer from as a result of their traumatic experiences and development under severe duress. There is much that remains to be understood about these complexities before therapeutic pathways can be offered that bridge local idioms of distress, local knowledge, and informed individual, family, or collective therapeutic interventions.

Second, that spirits and witches form integral part of children's local moral worlds and help their discursive reflection does not in itself determine the therapeutic effectivity of local resources that respond to these spirits and witches. Hollan (2004) maintains that too often idioms of distress are interpreted as always and naturally leading to solutions, and that these idioms may also backfire and engender precisely the distress that in another instance they help solve. Understanding phenomena through the lenses of witchcraft and evil spirits may reshape vague sensations or attributions into exacerbated anxiety both within the individual child and within their social environment (Kirmayer \& Blake, 2009; Nichter, 2010). Excluding inquiries into states of trance and dissociation, research into witchcraft beliefs and spirit possession in Africa has been conducted almost entirely from a social science perspective. In view of the alarming increase of children's involvement in witchcraft accusations and spirit possession, there is an urgent need for interdisciplinary research into the microprocesses that lead to children being haunted or accused, including what transpires on emotional and physiological levels. By exploring the reciprocal looping feedbacks of culturally constituted cognitive-emotive processes as well as physiological and social processes, along the lines of the research agenda set out in Hinton and Good (2009; cf. Hinton, Um, \& Ba, 2001), we may design interventions that will change the vicious circles contributed to by attributions of witchcraft or haunting spirits into virtuous circles. Symbolic healing may prove to be an intrinsic element of the design of such interventions. For the transactional processes involved in such healing to be effective, the various models of experiential and moral reality in which it can be framed must also be matters of critical inquiry, including traditional and psychological or psychiatric approaches. The extent to which these models are contested in local contexts is also of paramount importance. 


\section{Acknowledgements}

Earlier drafts of this article were presented in 2009 in the panel "Medical Anthropology \& Conflict" at the international conference Medical Anthropology at the Intersections: Celebrating 50 Years of Interdisciplinarity, Yale University, New Haven, US, September 24-27; and in 2011 in the panel "Local Responses to Trauma and PTSD: Therapeutic Mechanisms" at the annual meeting of the American Anthropological Association, Montreal, Canada, November 16-20, 2011. I thank the members of these panels, in particular the organizers Emma Varley (Yale) and Devon E. Hinton (AAA), as well as the members of the AISSR Children and Youth research group for their invaluable supporting criticism. I am also grateful to the Transcultural Psychiatry reviewers for their help in restructuring and improving my argument.

\section{Funding}

This research received no specific grant from any funding agency in the public commercial, or not-for-profit sectors.

\section{Notes}

1. On African symbolic healing and spirit possession see for example De Jong \& Reis (2010); Igreja (2007); Igreja et al. (2010); Reis (1993, 1996, 1997, 2000, 2002); van Dijk et al. (2000). On child medical anthropology see for example Akello (2010); Akello et al. (2006); Akello et al. (2010); Akello et al. (2009); Berckmoes (2007); Reis (2007, 2011); Reis and Dedding (2004); Rosenkrantz-Lindegaard (2009); Tize (2011); Tol (2009); Tol et al. (2009); Tol et al. (2010); Upadhaya (2011); van Reeuwijk (2010); Wasike Mangeni (2007).

2. Liu et al. (2005) report that elders and ritual specialists believe cen enter the mind or body of the sufferer in the form of visions and nightmares. Although there is no mention of trance, there is a thin line with dissociation phenomena here (cf. van Duijl, Nijenhuis, Komproe, Gernaat, \& De Jong, 2010). The difference between being haunted (in the sense of a harassing spirit experienced as external to the self) or being possessed (in the sense of a spirit entering and partly overtaking the self) is similarly ambivalent and sometimes a matter of perspective (e.g., others judging a haunted child to be possessed). Unlike other authors, Neuner et al. (2012) frame cen unambiguously in the context of trance and dissociation. This seems due to their objective to establish the validity of harmful spirit possession (in casu cen) as a psychological disorder classifiable in the DSM, and their construction of a cen spirit possession scale from a small exploratory pilot using a purposive sample of former child soldiers and based on and adapted to DSM-IV criteria. Due to selection bias of the construction of his instrument one may wonder whether the instrument's construct validity is sufficient for studying the nuances of experiences of cen and its underlying suffering among the population outside of the category of former child soldiers.

3. See Santos-Granero (2002) for a description of child sorcery in Peru, and Roper (2000) for a child-witch craze in Germany in the early 18th century.

4. For in-depth descriptions of the life worlds of children in this period see Akello (2010) and Angucia (2010).

5. See Quinlan and Quinlan (2007) for a comparative enquiry into the influence of adverse social conditions on parenting patterns and the relation with witchcraft beliefs.

6. For example Christensen (1998); De Bruijn, van Dijk, \& Gewald (2001); Honwana and De Boeck (2005); James, Jenks, \& Prout (1998); Lee (1999); Mayall (2000); Prout (2002); Reis and Dedding (2004); van Reeuwijk (2010); Woodhead and Faulkner (2000). 
7. See Finnstrom (2006) for Acholi warfare blessings and curses.

8. This makes it difficult to unambiguously categorize cen as "harmful spirit possession" (Igreja et al. 2010), or the relationship between child and spirit as "harm and exorcism" (Bourguignon, 2005). Whereas the relationship is not one of "service and protection," some children's return to arms to accommodate the spirit resonates with "propitiation and alliance," the second type in Bourguignon's classification.

9. Primary research for this project was conducted over a period of 7 months in 2005. Its findings are based on over 800 interviews (qualitative structured and quantitative) in 16 internally displaced camps in Acholiland with key informants knowledgeable of Acholi traditions and formerly abducted and displaced persons. Different religious groups and NGOs were also interviewed, and case studies took place in which ceremonies and communal cleansing rituals were observed and participants interviewed with the help of semistructured questionnaires. See Liu et al. (2005) for a more extensive description of the background and methodology.

10. The report speaks of a sacrificial animal here, but in ritual terms the animal is a scapegoat.

11. As well as exposure and other specific mechanisms now adhered to by contemporary competing psychotherapeutic schools.

\section{References}

Adinkrah, M. (2011). Child witch hunts in contemporary Ghana. Child Abuse and Neglect, $35(9), 741-752$.

Akello, G. (2010). Wartime children's suffering and quests for therapy in Northern Uganda (Vol. 25). Leiden, the Netherlands: African Studies Centre.

Akello, G., Reis, R., Ovuga, E. R., Rwabukwali, C. B., Kabonesa, C., \& Richters, A. (2006). Primary school children's perspectives on common diseases and medicines used: Implications for school health programmes and priority setting in Uganda. African Health Sciences, 17(2), 74-80.

Akello, G., Reis, R., \& Richters, A. (2010). Silencing distressed children in the context of war in Northern Uganda: An analysis of its causes and its health consequences. Social Science \& Medicine, 71(2), 213-220.

Akello, G., Richters, A., \& Reis, R. (2009). Coming to terms with accountability: Why the reintegration of former child soldiers in Northern Uganda fails. In P. GobodoMadikizela, \& C. van der Merwe (Eds.) Memory, narrative, and forgiveness: Perspectives on the unfinished journeys of the past (pp. 188-212). Cambridge, UK: Cambridge Scholars Publishing.

Angucia, M. (2010). Broken citizenship: Formerly abducted children and their social reintegration in Northern Uganda. Amsterdam, the Netherlands: Rozenberg.

Anyeko, K., Baines, E., Komakech, E., Ojok, B., Owor Ogora, L., \& Victor, L. (2012). "The cooling of hearts": Community truth-telling in Northern Uganda. Human Rights Review, 13(1), 107-124.

Baines, E. K. (2007). The haunting of Alice: Local approaches to justice and reconciliation in Northern Uganda. The International Journal of Transitional Justice, 1((1), 91-114.

Berckmoes, L. (2006). Growing up in a refugee camp: Constructions of identity among Burundian youth in Tanzania (Unpublished master's thesis). Universiteit van Amsterdam, the Netherlands.

Bluebond-Langner, M. (1978). The private worlds of dying children. Princeton, NJ: Princeton University Press. 
Bourguignon, E. (2005). Spirit possession. In C. Casey, \& R. B. Edgerton (Eds.) A companion to psychological anthropology. Modernity and psychocultural change (pp. 374-388). Malden, MA: Blackwell.

Brain, R. (1970). Child witches. In M. Douglas (Ed.) Witchcraft confessions and accusations. London, UK: Routledge.

Cahn, N. (2006). Poor children: Child "witches" and child soldiers in sub-Saharan Africa. Ohio State Journal of Criminal Law, 3, 413-456.

Christensen, P. H. (1998). Differences and similarity: How children's competence is constituted in illness and its treatment. In I. Hutchby, \& J. Moran-Ellis (Eds.) Children and competence: Arenas of action (pp. 187-201). London, UK: The Falmer Press.

Christensen, P. H. (2000). Childhood and the cultural construction of vulnerable bodies. In A. Prout (Ed.) The body, childhood and society (pp. 38-59). New York, NY: Macmillan Press.

De Boeck, F. (2005). The divine seed: Children, gift and witchcraft in the Democratic Republic of Congo. In A. Honwana, \& F. De Boeck (Eds.) Makers and breakers: Children and youth in postcolonial Africa (pp. 188-214). Oxford, UK: James Currey.

De Bruijn, M. D., van Dijk, R., \& Gewald, J.-B. (2001). Strength beyond structure: Social and historical trajectories of agency in Africa. In M. De Bruijn, R.van Dijk, \& D. Foeken (Eds.) Mobile Africa: Changing patterns of movement in Africa and beyond-African dynamics 1 (pp. 263-285). Leiden, the Netherlands: Brill.

De Jong, J. T. (2010). A public health framework to translate risk factors related to political violence and war into multi-level preventive interventions. Social Science \& Medicine, 70(1), 71-79.

De Jong, J. T., \& Reis, R. (2010). Kiyang-yang, a West-African post-war idiom of distress. Culture, Medicine and Psychiatry, 34(2), 301-332.

De Jong, J., \& Reis, R. (2013). Collective trauma processing: Dissociation as a way of processing postwar traumatic stress in Guinea Bissau. Transcultural Psychiatry, 50(5), 644-661.

Dickson Gomez, J. (2002). The sound of barking dogs: Violence and terror among Salvadoran families in the postwar. Medical Anthropology Quarterly, 16(4), 415-438.

Douglas, M. (1973). Natural symbols: Explorations in cosmology. London, UK: Barry \& Jenkins.

Dow, J. (1986). Universal aspects of symbolic healing: A theoretical synthesis. American Anthropologist, 88(1), 56-69.

Ensink, K., \& Robertson, B. (1996). Indigenous categories of distress and dysfunction in South African Xhosa children and adolescents as described by indigenous healers. Transcultural Psychiatry, 33(2), ), 137-172.

Evans-Pritchard, E. E. (1976). Witchcraft, oracles, and magic among the Azande. Oxford, UK: Clarendon. (Original work published 1937).

Finnstrom, S. (2006). Wars of the past and war in the present: The Lord's Resistance Movement/Army in Uganda. Africa: The Journal of the International African Institute, 76(2), 200-220.

Geschiere, P. (1997). The modernity of witchcraft: Politics and the occult in postcolonial Africa. Charlottesville: University of Virginia Press.

Geschiere, P. (1998). Globalization and the power of indeterminate meaning: Witchcraft and spirit cults in Africa and East Asia. Development and Change, 29(4), 811-837. 
Hammond-Tooke, W.D. (1986). The Aetiology of Spirit in Southern Africa. African Studies, 45(2), 157-170.

Hinton, D., \& Good, B. J. (2009). A medical anthropology of panic sensations. Ten analytic perspectives. In D. E. Hinton, \& B. J. Good (Eds.) Culture and panic disorder (pp. 57-81). Stanford, CA: Stanford University Press.

Hinton, D., Um, K., \& Ba, P. (2001). Kyol goeu ("Wind overload") Part I: A cultural syndrome of orthostatic panic among Khmer refugees. Transcultural Psychiatry, 38(4), 403-432.

Hollan, D. (2004). Self systems, cultural idioms of distress, and the psycho-bodily consequences of childhood suffering. Transcultural Psychiatry, 41(1), 62-79.

Honwana, A. (2002). Negotiating post-war identities: Child soldiers in Mozambique and Angola. In G. Bond, \& N. Gibson (Eds.) Contested terrains and constructed categories. Boulder, CO: Westview Press.

Honwana, A. (2005). Innocent and guilty: Child-soldiers as interstitial and tactical agents. In A. Honwana, \& F. De Boeck (Eds.) Makers and breakers: Children and youth in postcolonial Africa (pp. 31-52). Oxford, UK: James Currey.

Honwana, A., \& De Boeck, F. (2005). Makers and breakers: Children \& youth in postcolonial Africa. Oxford, UK: James Curry.

Igreja, V. (2007). The monkey's sworn oath: Cultures of engagement for reconciliation and healing in the aftermath of the civil war in Mozambique (Unpublished doctoral dissertation). University of Leiden, the Netherlands.

Igreja, V., Dias-Lambranca, B., Hershey, D. A., Racin, L., Richters, A., \& Reis, R. (2010). The epidemiology of spirit possession in the aftermath of mass political violence in Mozambique. Social Science \& Medicine, 71(3), 592-599.

James, A., Jenks, C., \& Prout, A. (1998). Theorizing childhood. Cambridge, UK: Polity Press.

Janzen, J. J. (1992). Ngoma: Discourses of healing in central and Southern Africa. Berkley: University of California Press.

Jordans, M. J. D., Tol, W. A., Komproe, I. H., \& De Jong, J. T. V. M. (2009). Systematic review of evidence and treatment approaches: Psychosocial and mental health care for children in war. Child and Adolescent Mental Health, 14(1), 2-14.

Kiev, A. (1972). Transcultural psychiatry. Harmondsworth, UK: Penguin.

Kirmayer, L. J. (1989). Cultural variations in the response to psychiatric disorders and emotional distress. Social Science \& Medicine, 29(3), 327-339.

Kirmayer, L. J., \& Blake, C. (2009). Theoretical perspectives on the cross-cultural study of panic disorder. In D. E. Hinton, \& B. J. Good (Eds.) Culture and panic disorder (pp. 31-56). Stanford, CA: Stanford University Press.

Kleinman, A., \& Kleinman, J. (1991). Suffering and its professional transformation: Toward an ethnography of interpersonal experience. Culture, Medicine and Psychiatry, 15(3), 275-301.

Lee, N. (1999). The challenge of childhood: Distributions of childhood's ambiguity in adult institutions. Childhood, 6(4), 455-474.

Lévi-Strauss, C. (1963). Structural anthropology. New York, NY: Basic Books.

Lewis, I. M. (2003). Ecstatic religion. A study of shamanism and spirit possession (3rd ed.). London, UK: Routledge. (Original work published 1971).

Liu Institute, Gulu District NGO Forum, \& Ker Kwaro Acholi. (2005). Roco Wat I Acoli. Restoring relationships in Acholi land: Traditional approaches to justice and reintegration. Retrieved from http://www.ligi.ubc.ca/sites/liu/files/Publications/JRP/15Sept2005_Roco _Wat_I_Acoli.pdf 
Marwick, M. (1950). Another modern anti-witchcraft movement in East Central Africa. Africa, 20(2), 100-112.

Mayall, B. (2000). The sociology of childhood: Children's autonomy and participation rights. In A. Smith, M. Gollop, K. Marshall, \& K. Nairn (Eds.) Advocating for children: International perspectives on children's rights (pp. 126-140). Dunedin, New Zealand: University Otago Press.

Mpyangu, C. M. (2010). The Acholi worldview. Why rituals are important for the reintegration of formerly abducted girls in Northern Uganda. In B. Maeland (Ed.) Culture, religion and the reintegration of female child soldiers in Northern Uganda (pp. 101-114). New York, NY: Peter Lang.

Neuner, F., Pfeiffer, A., Schauer-Kaiser, E., Odenwald, M., Elbert, T., \& Ertl, V. (2012). Haunted by ghosts: Prevalence, predictors and outcomes of spirit possession experiences among former child soldiers and war-affected civilians in Northern Uganda. Social Science \& Medicine, 75(3), 548-554.

Ngubane, H. (1977). Body and mind in Zulu medicine: An ethnography of health and disease in Nyuswa-Zulu thought and practice. London, UK: Academic Press.

Nichter, M. (1981). Idioms of distress: Alternatives in the expression of psychosocial distress: A case study from South India. Culture, Medicine and Psychiatry, 5(4), 379-408.

Nichter, M. (2010). Idioms of distress revisited. Culture, Medicine \& Psychiatry, 34(2), 401-416.

Obeyesekere, G. (1990). The work of culture: Symbolic transformation in psychoanalysis and anthropology. Chicago, IL: University of Chicago Press.

Ocitti, J. P. (1973). African indigenous education. As practised by the Acholi of Uganda. Nairobi, Kenya: East African Literature Bureau.

Ortner, S. B. (2006). Anthropology and social theory. Culture, power and the acting subject. Durham, NC: Duke University Press.

Peterman, A., Palermo, T., \& Bredenkamp, C. (2011). Estimates and determinants of sexual violence against women in the Democratic Republic of Congo. American Journal of Public Health, 101(6), 1060-1067.

Prout, A. (2002). Researching children as social actors: An introduction to the Children 5-16 Programme. Children \& Society, 16, 67-76.

Quinlan, R., \& Quinlan, M. (2007). Parenting and cultures of risk: A comparative analysis of infidelity, aggression and witchcraft. American Anthropologist, 109(1), 164-179.

Ranger, T. (2007). Scotland Yard in the bush: Medicine murders, child witches and the construction of the occult: A literature review. Africa: The Journal of the International Africa Institute, 77(2), 272-283.

Reis, R. (1993). Evil in the body, disorder of the brain: Interpretations of epilepsy and the treatment gap in Swaziland. Tropical \& Geographical Medicine, 46(3), S40-43.

Reis, R. (1996). Sporen van ziekte. Medische pluraliteit en epilepsie in Swaziland [Traces of illness. Medical plurality and epilepsy in Swaziland]. Amsterdam, the Netherlands: Het Spinhuis.

Reis, R. (1997). Menselijk materiaal als medicijn: over rituele moord in Swaziland [Human material as medicine: On ritual murder in Swaziland]. Medische Antropologie, 9(2), $362-376$.

Reis, R. (2000). The wounded healer as ideology: The work of ngoma in Swaziland. In R. van Dijk, R. Reis, \& M. Spierenburg (Eds.) The quest for fruition through 
ngoma: Political aspects of healing in Southern Africa (pp. 61-75). Oxford, UK: James Currey.

Reis, R. (2002). Medical pluralism and the bounding of traditional healing in Swaziland. In W. Ernst (Ed.) Plural medicine, tradition and modernity, 1800-2000 (pp. 95-112). London, UK: Routledge.

Reis, R. (2007). Inventing a generation: The revitalisation of umcwasho in Swaziland in response to the HIV/AIDS crisis. In E. Alber, S. van der Geest, \& S. Reynolds Whyte (Eds.) Generations in Africa: Connections and conflicts (pp. 163-182). Berlin, Germany: LIT Verlag.

Reis, R. (2011). Depressive devitalization and pervasive refusal syndrome: New child idioms of distress? In M. Tankink, \& M. Vysma (Eds.) Roads and boundaries. Travels in search of (re) connection (pp. 176-186). Diemen, the Netherlands: AMB Publishers.

Reis, R., \& Dedding, C. (2004). Kinderen als medeonderzoekers: Mogelijkheden en problemen van kind-gestuurd onderzoek [Children as co-researchers: Possibilities and problems of child-actor research]. Medische Antropologie, 16(1), 79-92.

Reynolds, P. (2005). Forming Identities. Conceptions of Pain \& Children's Expressions of it in Southern Africa. In A. Honwana, F. De Boeck, \& S. Reynolds Whyte (Eds.) Makers and Breakers. Children and Youth in Postcolonial Africa (pp. 81-101). Oxford, UK: James Currey.

Roberts, B., Odong, V. N., Browne, J., Ocaka, K. F., Geissler, W., \& Sondorp, E. (2009). An exploration of social determinants of health amongst internally displaced persons in Northern Uganda. Conflict and Health, 3 (10) doi:10.1186/1752-1505-3-10

Roper, L. (2000). Evil imaginings and fantasies: Child-witches and the end of the witch craze. Past \& Present, 167(1), 107-139.

Rosenkrantz-Lindegaard, M. (2009). Coconuts, gangsters and rainbow fighters. How male youngsters navigate situations of violence in Cape Town, South Africa (Unpublished doctoral dissertation). University of Amsterdam, the Netherlands.

Santos-Granero, F. (2002). Saint Christopher in the Amazon: Child sorcery, colonialism and violence among the southern Arawak. Ethnohistory, 49(3), 507-543.

Seekings, J. (2006). Beyond heroes and villains: The rediscovery of the ordinary in the study of childhood and adolescence in South Africa. Social Dynamics, 32(1), 1-20.

Stobart, E. (2006). Child abuse linked to accusations of "possession" and "witchcraft". Research report RR 750. Nottingham, UK: Department for Education and Skills Publications.

Tize, C. (2011). Navigating a culture of fear. Transgenerational processes and structural violence in Nepal (Unpublished master's dissertation). University of Amsterdam, the Netherlands.

Tol, W. A. (2009). Healing in the aftermath of war. Conceptualisation and evaluation of mental health and psychosocial support for populations exposed to political violence in low-income settings (Unpublished doctoral dissertation). VU University Amsterdam, the Netherlands.

Tol, W. A., Jordans, M. J. D., Reis, R., \& De Jong, J. T. V. M. (2009). Ecological resilience: Working with child-related psychosocial resources in war-affected communities. In D. Brom, R. Pat-Horenczyk, \& J. Ford (Eds.) Treating traumatized children: Risk, resilience, and recovery (pp. 164-182). London, UK: Routledge.

Tol, W. A., Reis, R., Susanty, D., \& De Jong, J. T. V. M. (2010). The psychosocial impact of communal violence on children's ecologies and associated resources: 
Qualitative findings from central Sulawesi, Indonesia. Transcultural Psychiatry, 47(1), $112-135$.

Turner, V. (1981). The drums of affliction: A study of religious processes among the Ndembu of Zambia. Ithaca, NY: Cornell University Press. (Original work published 1968).

Upadhaya, N. (2011). "Distress, a door to happiness?" The meaning and etiology of everyday adolescent distress, in a Nepalese government high school (Unpublished master's thesis). University of Amsterdam, the Netherlands.

Van Acker, F. (2004). Uganda and the Lord's Resistance Army: The new order no one ordered. African Affairs, 103(412), 335-357.

Van Dijk, R., Reis, R., \& Spierenburg, M. (Eds.). (2000). The quest for fruition through ngoma: The political aspects of healing in Southern Africa. London, OH: James Currey/ Ohio Press.

Van Duijl, M., Cardeña, E., \& De Jong, J. T. (2005). The validity of DSM-IV dissociative disorders categories in South-West Uganda. Transcultural Psychiatry, 42(2), 219-241.

Van Duijl, M., Nijenhuis, E., Komproe, I. H., Gernaat, H. B. P. E., \& De Jong, J. T. (2010). Dissociative symptoms and reported trauma among patients with spirit possession and matched healthy controls in Uganda. Culture, Medicine and Psychiatry, 34(2), 380-400.

Van Nieuwenhuijsen, J. W. (1974). Diviners and their ancestor spirits: A study of the izangoma among the Nyuswa in Natal, South Africa. Amsterdam, the Netherlands: Universiteit van Amsterdam, ASC.

Van Reeuwijk, M. (2010). Because of temptations: Children, sex and HIV/AIDS in Tanzania. Diemen, the Netherlands: AMB.

Wasike Mangeni, J. B. (2007). Fever and everyday life in rural Uganda. Understanding children's perceptions, experiences and health-seeking behaviour within the household (Unpublished master's thesis). University of Amsterdam, the Netherlands.

Willis, R. (1999). Some spirits heal, others only dance: A journey into human selfhood in an African village. Oxford, UK: Berg.

Woodhead, M., \& Faulkner, D. (2000). Subjects, objects or participants? Dilemmas of psychological research with children. In P. Christensen, \& A. James (Eds.) Research with children: Perspectives and practices (pp. 9-35). London, UK: Falmer Press.

Ria Reis is Professor of Medical Anthropology at Leiden University Medical Centre (LUMC), Department of Public Health and Primary Care; Associate Professor at the Department of Sociology and Cultural Anthropology and joint Director of the research program Anthropology of Health, Care, and the Body at the Amsterdam Institute for Social Science Research (AISSR), the University of Amsterdam; and Fellow of the Leiden African Studies Centre, the Netherlands. Her current research focus is on young people's health perceptions and strategies and the transgenerational transference of vulnerabilities in contexts of inequality and (post)conflict, and on the articulation of ethnography within multidisciplinary research and interventions, particularly in collaborative projects with partners in policy and practice. Her graduate and doctoral students work on these issues in different areas of the world, but particularly in Africa. 